\title{
Justice Sensitivity in Intergroup Contexts: A Theoretical Framework
}

\author{
Anna Baumert ${ }^{1} \cdot$ Aya Adra² $\cdot$ Mengyao $\mathrm{Li}^{2}$
}

Accepted: 2 September 2021 / Published online: 29 January 2022

(c) The Author(s) 2021

\begin{abstract}
Individuals differ systematically in how much they are concerned with matters of justice or injustice. So far, in various domains of life, such as romantic relationships, work, and school contexts, dispositional justice sensitivity has been found to be a powerful predictor of individual-level processing and interpersonal behaviors. Yet, matters of justice and injustice often materialize at the group level, especially when conflicts about status, rights, and resources occur between groups. Here, we propose a theoretical framework to understand how different facets of justice sensitivity (i.e., victim, beneficiary/perpetrator, and observer sensitivities) are relevant for group-level processes in intergroup contexts. Integrating research on justice sensitivity and intergroup conflict, we develop several propositions regarding how and under which conditions justice sensitivity influences intergroup experiences, attitudes, and behaviors. We selectively review the existing empirical evidence that can speak to the validity of these propositions, and outline future research that can test our propositions.
\end{abstract}

\section{Justice Sensitivity in Intergroup Contexts: A Theoretical Framework}

Justice is a fundamental human value (Montada, 2007), concerning interpersonal relationships as well as relations within and between social groups and societies. Yet, individuals differ systematically in how sensitively they react toward potential injustice. While some readily perceive injustices surrounding them and react strongly, with intense emotion, recurring thoughts, and motivation to restore justice, others care less. These interindividual differences in justice sensitivity (JS) have

We thank Silja Petrig for helping to prepare the manuscript.

Anna Baumert

baumert@uni-wuppertal.de

1 University of Wuppertal and Max Planck Institute for Research On Collective Goods, Bonn, Germany

2 Max Planck Institute for Research On Collective Goods, Bonn, Germany 
been found to be relatively stable over time and consistent across types of injustice — such as distributive, retributive, or procedural-but differentiated according to the perspectives that one can adopt toward injustices (Baumert et al., 2014a; Schmitt et al., 2005, 2010). Accordingly, four facets of JS have been established, capturing responses when one experiences unjust disadvantage or treatment oneself (victim sensitivity), when passively benefitting from (beneficiary sensitivity) or actively committing an act of injustice (perpetrator sensitivity), or when witnessing injustices between others (observer sensitivity). Since the concept was first introduced by Schmitt (1996), it has attracted increasing interest by researchers from various disciplines, including social, personality, clinical, and developmental psychology, management, behavioral economics, sociology, and health and education sciences.

The JS perspectives have proven to be powerful predictors of justice-related experience and behavior. In a broad range of contexts, they seem to have important implications for how justice-related situations are processed and reacted to, but also how social situations are shaped (see Baumert \& Schmitt, 2016, for a review). For example, being sensitive to becoming the victim of injustice (victim sensitivity) has been found to be a unique predictor of anger, protest (Mohiyeddini \& Schmitt, 1997; Schmitt \& Mohiyeddini, 1996), and intentions to take revenge (Gollwitzer et al., 2005), reduced relationship and job satisfaction (Baumert et al., 2014a), as well as a reluctance to cooperate, paired with legitimizing thoughts of one's own norm transgressions (Gollwitzer et al., 2005). From a complementary perspective, being sensitive to the possibility of perpetrating injustices oneself (perpetrator sensitivity) involves anticipated feelings of guilt, prosocial behavioral tendencies, and a reluctance to violate fairness principles, even when it is tempting to do so (e.g., Schmitt et al., 2010).

So far, most conceptual work and empirical research has addressed how individual differences in the JS perspectives affect interpersonal interactions and relationships. Yet, matters of justice and injustice often materialize at the group level, especially when conflicts about status, rights, and resources occur between social groups. In the present paper, we ask how individual differences in the JS perspectives contribute to shaping group-level processes. We review those previous studies that have addressed JS in intergroup contexts. Extending the existing literature, we propose a theoretical framework to understand how and under which conditions individual differences in JS should influence intergroup experiences, attitudes, and behaviors. In our framework, we propose identification with a social group as a key determinant of whether individual-level JS would become relevant for group-level processes. We analyze how JS might invoke potential psychological conflicts between group-level and personal concerns. And, we spell out how the JS perspectives might function depending on the advantaged, disadvantaged, or bystander status of one's in-group. We discuss how our framework can direct future research toward a more complete understanding of the JS perspectives in intergroup contexts. 


\section{Justice Sensitivity-Lessons Learned}

In 2016, Baumert and Schmitt published a handbook chapter providing a comprehensive review of the conceptual developments and empirical research on JS, up to that date. Since then, a search on Google Scholar indicates that another 850 publications have appeared that mention JS as a concept, including 58 publications with the exact term in the title (GoogleScholar, 2021). Here, we do not aim to provide yet another comprehensive review. Instead, we want to summarize the understanding reached regarding psychological individual-level processes involved in the different JS perspectives. Moving beyond the individual level, since 2016, a small number of publications have addressed JS from a political psychological lens, specifically in intergroup contexts. We selectively review these studies. Together, these conceptual and empirical insights will form the basis for the theoretical framework for grouplevel implications of JS that we develop in the subsequent section.

\section{Justice Sensitivity and Individual-Level Processes}

Across the four facets of the JS perspectives, JS captures individual differences in the readiness to perceive injustice, the intensity of cognitive and emotional reactions to perceived injustice, and the resulting motivation to restore justice (Schmitt, 1996). Depending on the perspective, these components of JS play out in qualitatively different ways.

\section{Victim Sensitivity}

Higher (compared to lower) victim sensitivity entails the ready perception of unjust own victimization, repeated thoughts and intense anger when having experienced victimization, and strong intentions to protest and redress the injustice (Mohiyeddini \& Schmitt, 1997; Schmitt \& Mohiyeddini, 1996). In other words, victim-sensitive persons should be predisposed to stand up against being victimized. Further processes of victim sensitivity were spelled out in the Sensitivity to Mean Intentions (SeMI) model (Gollwitzer \& Rothmund, 2009; Gollwitzer et al., 2013). According to this model, victim sensitivity involves a hypersensitivity to cues indicating a threat of being exploited. Particularly in situations that are characterized by interdependence and social uncertainty (i.e., situations in which exploitation is possible), persons with high victim sensitivity (compared to persons with lower victim sensitivity) will react to slight signs of untrustworthiness with anticipation and fear of exploitation and a reluctance to cooperate. Motivated to avoid being exploited, they would rather commit norm violations themselves and readily legitimize such acts as justified means to prevent or make up for their own disadvantages.

Evidence for relevant consequences of victim sensitivity has accumulated. In anonymous interactions, studies employing so-called economic games have consistently found victim sensitivity to be negatively correlated with cooperative behavior. In a recent study with a Japanese sample, victim sensitivity was associated with reluctance to volunteer for a common good, mediated by angry anticipation of being 
the only volunteer (Tham et al., 2019). In line with earlier findings from Western samples (e.g., Gollwitzer \& Rothmund, 2011; Maltese et al., 2016), Baumert et al. (2020) also recently found that victim sensitivity predicted reduced cooperation under threat of exploitation in samples from the Philippines. Moving beyond anonymous interactions, in close interpersonal relationships, victim-sensitive persons were found to tend toward mistrustful interpretations of their partners' attempts at reconciliation after conflict, and a reluctance to forgive, coupled with intentions of revenge and legitimizing thoughts (Gerlach et al., 2012). In work contexts, highly victim-sensitive persons reacted with loss in self-esteem and counterproductive work behaviors when they perceived assigned tasks to be illegitimate (SchulteBraucks et al., 2019). In sum, victim sensitivity seems to entail self-oriented concerns about injustice, and sometimes rather antisocial consequences of a motivation to prevent or redress unjust victimization.

\section{Beneficiary and Perpetrator Sensitivities}

Complementary to the victim perspective, beneficiary and perpetrator sensitivity capture individual differences in the readiness to perceive oneself as benefitting from or actively committing injustices, respectively. From both perspectives, the typical affective reaction to perceived injustices involves guilt (e.g., Weiss et al., 1999), and persons with higher (compared to lower) beneficiary or perpetrator sensitivity tend to react more intensively with these emotions (Gollwitzer et al., 2005; Schmitt et al., 2010). Moreover, beneficiary and perpetrator sensitivity share a strong motivation to restore justice and compensate victims of injustices from which one benefitted or which one committed.

Empirical studies have highlighted the prosocial tendencies involved in beneficiary and perpetrator sensitivities and their underlying cognitive, emotional, and motivational processes. For instance, even under situational circumstances that tempted participants to behave egoistically, high (vs. low) beneficiary or perpetrator-sensitive individuals were more likely to share equally in dictator game settings (Lotz et al., 2013*1) and trust game settings (Baumert et al., 2020), and contributed more to a public good (Schlösser et al., 2018a*). Moreover, the prospect of being advantaged by fate compared to an anonymous interaction partner resulted in anticipated negative emotions for individuals high in beneficiary or perpetrator sensitivity and motivated solidarity with the disadvantaged partner (Stavrova \& Schlösser, $\left.2015^{*}\right)$. In a longitudinal study with young adults, beneficiary and perpetrator sensitivities were found to correlate negatively with tendencies of moral disengagement (Maltese \& Baumert, 2019). Among adolescents, perpetrator sensitivity was negatively correlated with bullying behavior (Bondü et al., 2016).

\footnotetext{
1 In some studies, authors chose to combine beneficiary, perpetrator and observer sensitivities into a measure of other-regarding JS (JS-others). In the present review, we mark these studies with * to indicate that in these cases it was not analyzed in detail which, if not all, of the other-regarding JS perspectives were responsible for the reported associations.
} 
Given their conceptual overlap in the shared elements of emotional and motivational reactions, measures of beneficiary and perpetrator sensitivity have been found to be positively correlated. Yet, confirmatory factor analyses also supported their distinctness (Baumert et al., 2014a; Schmitt et al., 2010). While the empirical results regarding prosocial inclinations largely align for beneficiary and perpetrator sensitivities, it seems plausible that perpetrator sensitivity should specifically entail the anticipation of guilt about and active avoidance of committing injustices (Baumert et al., 2021).

\section{Observer Sensitivity}

Similar to beneficiary and perpetrator sensitivities, observer sensitivity is thought to involve genuine other-regarding concerns for justice and prosocial inclinations. It describes individual differences in the readiness to perceive injustice that affects others, and the strength of cognitive, emotional, and motivational responses to observed injustice. Different from beneficiary and perpetrator sensitivities, it involves individual differences in intensity of anger and outrage experienced toward perpetrators of injustice. For observer sensitivity, the inherent motivation to restore justice manifests as punitive tendencies toward a perpetrator, as well as in solidarity toward victims of injustice.

In anonymous interactions in economic games, high (in comparison with lower) observer-sensitive persons have been found to intervene in situations of unfair allocations among others, despite costs to themselves. Observer sensitivity predicted higher third-party punishment of a perpetrator (Baumert et al., 2014b), mediated by outrage (Lotz et al., 2011*), but also costly compensation of victims of unfairness (Toribio-Flórez et al., 2021). Similar results emerged in more complex real-life situations. Observer sensitivity was found to predict anger experienced when confronted with others' norm violations, and indirectly facilitated taking action against such norm violations, despite personal risk (Sasse et al., 2020; see also Niesta Kayser et al., 2010). Rothschild and Keefer (2018) showed that the effects of observer sensitivity on moral outrage over a company's mistreatment of their employees and calls for retribution persisted, independently of the level of guilt that participants experienced, and were most pronounced after participants had affirmed their moral identity. In addition to how observer sensitivity shapes reactions to injustices committed by others, it has been found to be also a predictor of own adherence to fairness norms, including enhanced sharing (Baumert et al., 2014b, 2020), consistent contribution to public goods (Schlösser et al., 2018a*), and preferences for equal distributions over own advantages (Schlösser et al., 2018b*).

In sum, the JS perspectives involve distinct patterns of processing and reactions to potential injustice. The JS perspectives share their focus on how readily situations are perceived as unjust and how intensely people react emotionally and behaviorally to perceived injustice. Broadly distinguishing between perspectives, victim sensitivity appears to entail self-regarding concerns for justice and self-protection, and under certain conditions rather antisocial tendencies. Beneficiary, perpetrator, and observer sensitivities, by contrast, reflect other-regarding concerns for justice and involve prosocial inclinations. 


\section{Emerging Evidence for the Relevance of the JS Perspectives in Intergroup Contexts}

The bulk of the literature on JS has been focused on individual-level processes and interpersonal contexts. Nevertheless, there are several papers in which authors have addressed the relevance of the JS perspectives in political contexts and for grouplevel processes (e.g., Gollwitzer et al., 2021). Here, we selectively review those studies that shed light on the roles that the JS perspectives might play in intergroup contexts.

Regarding group positionalities, past work addressing JS in intergroup contexts has focused exclusively on advantaged groups. For example, Rothmund and colleagues $\left(2020^{*}\right)$ investigated the correlations between the JS perspectives and preferences for populist radical-right politicians or parties among White individuals in the USA and Germany. They found that victim sensitivity consistently predicted endorsement of right-wing populist agents, and that this relationship was mediated by heightened anti-immigration attitudes. By contrast, the other-regarding JS perspectives were negatively related to anti-immigration attitudes.

In a longitudinal study in the context of the German reunification, beneficiary sensitivity predicted continued willingness among West Germans to transfer tax money to former East German parts of the country (Gollwitzer et al., 2005). Victim sensitivity, by contrast, was predictive of relative increases in group-based anger among West Germans (experienced toward East Germans) and worry about the future of their group (Süssenbach \& Gollwitzer, 2015). In the context of the Euro crisis that had unfolded starting in 2010, Rothmund et al. (2017) found that, among Germans, observer sensitivity correlated with enhanced empathy toward, and support for solidarity with European countries in need of financial transfers. By contrast, victim sensitivity was associated with less support for solidarity, mediated by heightened nationalistic concerns and resentment toward debtor countries, and lower empathy toward them.

Complementing these correlational findings with experimental approaches, Süssenbach and Gollwitzer (2015) and Rothmund et al. (2017) found consistent evidence that victim-sensitive individuals reacted particularly negatively to news reports stressing potential exploitative intentions among groups seeking support from the participants' own group. Such news framing in the context of the Euro crisis led to increased nationalistic concerns and reduced solidarity among victimsensitive (compared to less victim-sensitive) persons, but did not diminish the positive association of observer sensitivity with solidarity. Similarly, news reports claiming exploitative intentions among asylum seekers triggered strong anger reactions among highly victim-sensitive (compared to less victim-sensitive) Germans. Observer sensitivity, by contrast, retained a positive relation with compassion, independent of the news report framing.

Taken together, these findings suggest that individual differences in the JS perspectives might be relevant for how individuals construe and react to relationships between their group and other groups. Among arguably advantaged group members, these studies revealed meaningful relations between the JS perspectives and intergroup attitudes (e.g., anti-immigration attitudes), emotion (e.g., group-based anger 
and fear), and behavioral inclination (e.g., solidarity in terms of support for tax transfers or financial credits).

In addition to the reviewed studies, there is emerging interest in how the JS perspectives relate to the endorsement of radical or violent means for political goals. This line of research is relevant for intergroup contexts as well, as it touches on conflict between opposing groups in society, and the ways in which group members approach these conflicts. However, results are quite mixed. For instance, in a heterogeneous sample of the Dutch population, victim sensitivity was related to feelings of personal and group-based relative deprivation (fraternal deprivation, Runciman \& Runciman, 1966, and other risk factors of radicalization), and these in turn were associated with support for violent political organizations (Macdougall et al., 2018). Among German adolescents (Jahnke et al., 2020), victim sensitivity was also related to stronger endorsement of violence as a means to achieve political goals generally, and specifically as a means to achieve right-wing group goals. In this sample, observer sensitivity was negatively related to such endorsements. In a further study with young adult and mostly left-wing activists, participants were asked to indicate a political group that they strongly identified with, and then to report their intentions to engage in different kinds of activism on behalf of this group. Notably, in this study, observer (and not victim) sensitivity was related to legal as well as radical activism intentions. Taken together, these studies suggest that there exists a relationship between the JS perspectives and group-based radicalization processes, albeit the nature of this relationship is still far from conclusive.

\section{Summary and Desiderata}

As Rothmund et al. (2017) highlighted, those psychological processes shown to shape the consequences of JS in interpersonal contexts "might also be at work on an intergroup level" (p. 50). Dispositional differences in the JS perspectives potentially shape how individuals construe relationships among groups, particularly concerning those that they identify with as group members. As a consequence, the JS perspectives might be decisive for how individuals react to situational affordances and demands that do not necessarily affect them directly as individuals, but have implications for their group.

So far, however, the empirical evidence is limited, and the conceptual analysis has been incomplete, with regard to how and under what conditions JS might play out in intergroup contexts. First of all, the few existing studies on JS in intergroup contexts did not include any measures of the quality or degree of identification with the relevant social group. As Süssenbach and Gollwitzer (2015) pointed out, it remains unknown how much participants actually appraised the relevant situations as identified members of the pertinent social group rather than as individuals. Second, and relatedly, the reported study setups entail the possibility that individuals construed themselves as personally affected (e.g., having to pay more taxes), rather than focused on group-level consequences (e.g., West Germans transferring money to East Germany). Rothmund et al. (2017) suggested that for future research, it could be worthwhile to disentangle personal from group-level concerns. In the subsequent section, we will analyze in more detail how these concerns can be aligned or in 
potential conflict, depending on contextual characteristics and individual differences in JS perspectives. Third, the reported studies also share a sole focus on the roles of the JS perspectives among members of an advantaged group in the respective intergroup context. However, it is possible that the JS perspectives play out differently for intergroup experiences, attitudes, and behaviors, depending on a social group's positionality as being advantaged, disadvantaged, or a bystander to intergroup inequality or conflict.

\section{A Theoretical Framework for JS and Intergroup Processes}

We start our theoretical outline from the basic proposition that personality dynamics can become relevant for group-level processes, specifically in intergroup contexts, when individuals identify as members of a social group. Personality dynamics capture the characteristic ways in which individuals process information and relate and react to the world (Funder, 2004). In that sense, personality traits describe relatively stable interindividual differences in patterns of processing and reactions to (mostly social) information (Baumert et al., 2017). As highlighted in social identity theory (Tajfel, 1978; Tajfel et al., 1979; Turner et al., 1987), individuals can construe themselves and their relations to the world as a unique individual, or as a member of a social group (besides further levels of construal). To the extent that a person identifies with a social group in a particular moment, they will process and react to information as a group member. We propose that personality does not become irrelevant in such moments, but can shape the ways in which a person construes the relationship between their group and other groups, and how they react to this construal. Since perceptions of and reactions to injustices are psychological phenomena that occur at the group level as much as at the interpersonal level, we argue that the JS perspectives should be relevant at both.

In the following, we present our theoretical framework (see Fig. 1) that details how and under which conditions the JS perspectives could shape group-level perceptions of injustice, and consequent intergroup emotion and behavior. For our framework, we draw heavily on social identity theory (Tajfel et al., 1979), intergroup-emotions theory (Smith, 1993), and the dynamic dual-pathway model of approach coping with collective disadvantage (van Zomeren et al., 2012). We integrate insights from these theories with the conceptual and empirical understanding of the JS perspectives, as reviewed above. We will highlight the ways in which intergroup processes involved in the JS perspectives should play out in parallel or differently from those processes at the individual level.

\section{Group Positionalities as Contextual Demands}

In our framework, we assume that group positionalities, including the relative standing of social groups with regard to status, power, and other resources, can provide relevant situational affordances and demands for group-level experiences and 


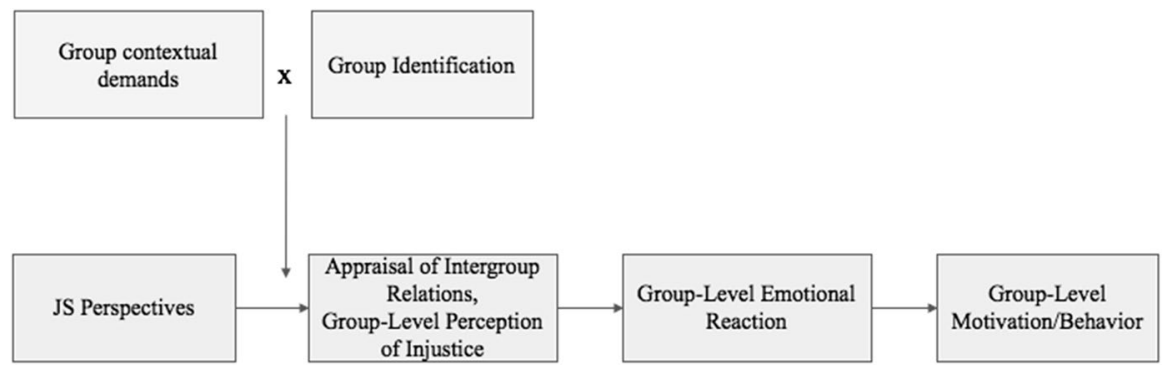

Fig. 1 Path Model Depicting the Theoretical Framework for Justice Sensitivity in Intergroup Contexts

behavior (e.g., Crosby, 1976; Merton \& Kitt, 1950; Walker \& Smith, 2002). Furthermore, we take a social identity perspective and assume that, when a person identifies strongly as a group member, their group's circumstances are self-relevant, independent of any individual concerns that might be affected or not. As such, their group's circumstances pose relevant contextual demands that the person has to cope with. This notion is fully in line with the reasoning underlying the dynamic dual-pathway model of approach coping with collective disadvantage (von Zomeren et al., 2012). Indeed, the authors state: "... structural discrimination (e.g., based on gender, race, or ethnicity) and other collective disadvantages (e.g., higher taxes, environmental issues) are important contextual demands with which people cope" (p. 184). However, while the dynamic dual-pathway model is specifically concerned with coping with collective disadvantage, we extend this notion to encompass relative advantage of an in-group (Leach et al., 2002) as well as a group's bystander status relative to other groups' disadvantages or conflicts (e.g., Saab et al., 2015) as contextual demands. $^{2}$

\section{Group Identification as a Moderator}

As stated above, we consider identification with a social group to be a key boundary condition that determines whether and to which extent group circumstances are psychologically relevant for an individual. For people who identify strongly as members of a group, their group's positionalities are self-relevant as contextual demands. For individuals who do not identify or only weakly identify with a group, their appraisals and reactions will depend on how their individual interests or personal concerns are affected in a particular situation, rather than on their group's circumstances per

\footnotetext{
2 Note, that group positionalities are relative to specific group constellations, and not absolute characteristics of groups. Furthermore, distinctions between group positionalities can be much more fine-grained, beyond advantaged, disadvantaged, and bystander groups. For simplicity, we use this distinction in the present framework. We note, however, that more detailed differentiations could be relevant when spelling out certain interactions between group positionalities and the JS perspectives. For example, advantaged group members can arguably be further divided into (direct, or current) perpetrators and (indirect, or historical) beneficiaries, and this division could inform diverging hypotheses on how the contextual demands associated with advantaged group membership interact with perpetrator and beneficiary JS respectively.
} 
se (von Zomeren et al., 2012). In that sense, we posit that identification with a group "shifts" psychological processes from the individual level to the group level.

Since the relevance of the JS perspectives for individual-level processes is relatively well researched (see our review above), we propose a framework that helps understand the various ways in which the JS perspectives might become relevant at the group level. Based on the social identity perspective, we focus on how the JS perspectives might shape processes among people who are strongly identified with their group. This is not to say that the JS perspectives should be irrelevant among persons who only weakly identify with their group, but for such people, the decisive factor is likely to be the way that they perceive a potential injustice to affect or relate to them as individuals (rather than as group members).

\section{Group-level Appraisals and Resulting Intergroup Emotions and Behavior}

\section{Group-level Perceptions of Injustice}

To the extent that a person identifies as a member of a social group, they will engage in group-level social comparison and appraise their group's standing relative to other groups as self-relevant (Runciman \& Runciman, 1966). Drawing on appraisal theories (e.g., Mikula, 2003; see Scherer et al., 2001), we know that perceptions of injustices result when situations are perceived as illegitimate (i.e., entitlements or rights are seen to be violated) and when blame is attributed (i.e., an intentional agent, self or other, is seen as responsible for and under control of the circumstances, or no justifications are accepted; Alicke, 2000; Shaver, 1985). While appraisal theories often focus on individual-level processes in interpersonal contexts, they can inform our thinking about group-level appraisals (for a similar argument, see van Zomeren et al., 2012). Independent of how they are affected as individuals, people can perceive intergroup relations as illegitimate and attribute blame to certain groups or group representatives (including their own).

\section{Intergroup Emotion and Behavior Resulting from Perceived Group-level Injustice}

As spelled out in intergroup-emotion theory (e.g., Mackie et al., 2008; Smith \& Mackie, 2015), group-level appraisals can trigger group-based emotions, meaning emotions experienced by group members on behalf of their group, independent of any personal concerns (Iyer \& Leach, 2008). While the subjective experiences and psychological consequences regarding arousal and information processing are thought to be similar between such group-based emotions and individual-level emotions, group-based emotions are specific due to their group-level appraisal patterns, as well as to their group-relevant behavioral consequences. Indeed, an important function of group-based emotions is the regulation of intergroup behaviors, such as intergroup discrimination, solidarity, or protest.

Qualitatively different group-based emotions with their specific inherent behavioral tendencies have been investigated among disadvantaged, advantaged, and (albeit less so) bystander groups (e.g., Li \& Leidner, 2019). For instance, among 
disadvantaged groups, anger has been identified as a critical emotion that fuels collective action against disadvantage (e.g., Smith et al., 2008; van Zomeren et al., 2004; Walker \& Smith, 2002). Among advantaged groups, collective guilt (i.e., guilt experienced on behalf of one's group's wrongdoings or complicities) has attracted scientific attention (e.g., Leach et al., 2006), together with processes of cognitive disengagement that work against experiences of collective guilt (Leach et al., 2002). Bystander groups have received less attention, but some studies point to moral outrage and sympathy as emotional responses among bystander group members, that are predictive of intergroup solidarity (Saab et al., 2015).

\section{Individual Differences in Group-level Appraisals and Resulting Intergroup Emotions}

In our framework, we emphasize that the emotional experiences resulting from perceived injustices at the group level should critically depend on how the individual group member construes the relation of their group to other groups. Clearly, the contextual demands of disadvantaged, advantaged, and bystander groups diverge substantially (Turner et al., 1987). Moreover, as proposed by intergroup-emotion theory, certain group-level emotional experiences can become part of the group identity, so that rather stereotypical emotions might be expressed by identified members of one group ("emotional self-stereotyping," Mackie et al., 2008, p. 1871). Despite these potential restrictions on individual differences, individual members who identify with the same social group could still largely differ in their group-level social comparisons, and the subsequent appraisals that they engage in. For example, some members of disadvantaged groups have been found to engage in downward social comparisons, when they care about groups that might be worse off or equally disadvantaged as their group, when they worry about losing privileges that their group holds as opposed to other groups (e.g., Ball \& Branscombe, 2019), or when they downplay their group's disadvantage (e.g., Jost et al., 2002). Among advantaged group members, Leach et al., (2002) have spelled out the various patterns of grouplevel appraisals that could give rise to qualitatively very different emotional experiences. For example, advantaged group members could feel anxious and worry about the possibility of losing their group's privilege, or they could feel guilty, depending on whether they perceive their group as being in control of the circumstances or not.

\section{How the JS Perspectives Shape Perceptions of and Reactions to Injustices in Intergroup Contexts}

We propose that when individuals identify strongly with a social group, individual differences in JS come to play a role in how their group's circumstances relative to other groups are appraised. Generally speaking, higher (compared to lower) scores on any of the JS perspectives should result in a greater readiness to perceive group constellations as unjust. According to our framework, group-level appraisals should be jointly shaped by contextual demands and the JS perspectives. Beyond 
the individual readiness to perceive injustice, further core components of JS are the intensities of emotional, cognitive, and behavioral responses to perceived injustices (Schmitt, 1996). Therefore, in intergroup contexts, when individuals identify strongly with their group, the JS perspectives should also modulate how strongly these group members react to perceived group-level injustice.

More specifically, each JS perspective should entail a characteristic pattern of group-level social comparisons and appraisals, and shape specific emotional and behavioral responses, depending on the contextual demands posed by disadvantaged, advantaged, or bystander group positionalities. Next, we will spell out how these group-level processes might be shaped by the JS perspectives. For each JS perspective, we start with the group positionality that most directly matches it (see Table 1 for an overview).

\section{Victim Sensitivity at the Group Level}

Parallel to individual-level processes, victim sensitivity should involve heightened concerns for justice for the in-group. Thus, among persons who identify strongly with a social group, persons with high (compared to lower) victim sensitivity should readily perceive or anticipate illegitimate disadvantages for their in-group, attribute blame to out-groups, reject justification of their perceived disadvantages, and resist conciliatory efforts from the adversarial group.

Since the contextual demands of disadvantaged groups afford perceptions of past and/or ongoing unjust victimization, we propose that victim sensitivity should be predictive of such perceptions (i.e., experience of fraternal deprivation) among highly identified members of disadvantaged groups. Furthermore, among disadvantaged groups, highly identified members with high (compared to lower) victim sensitivity should react with more intense anger to perceiving their in-group as unjustly victimized, and they should be inclined to engage in protest and aim to redress the injustice. In other words, victim sensitivity might be a personality predictor of engagement in collective action among the disadvantaged. However, it seems plausible that victim-sensitive group members will engage in action on behalf of their group, and be reluctant to fight in solidarity on behalf of other disadvantaged groups (Noor et al., 2017), in line with notions of exclusive or competitive victim beliefs. Since victim sensitivity is associated with legitimizing cognitions regarding own norm violations at the individual level (Gollwitzer et al., 2005), it could foster endorsement of non-normative means (e.g., use of violence) to achieve group goals among highly identified disadvantaged group members.

For advantaged group members, in contrast, contextual demands may afford the anticipation of future unjust disadvantage or loss of subjectively legitimate privilege (e.g., Nelson et al., 2018), and accordingly, we hypothesize that victim sensitivity should be predictive of anticipation of injustices toward the advantaged in-group, among highly identified members. For example, when advantaged groups are confronted with calls for reparation or punishment, victim-sensitive (as opposed to less victim-sensitive) individuals who identify with their group should readily perceive 


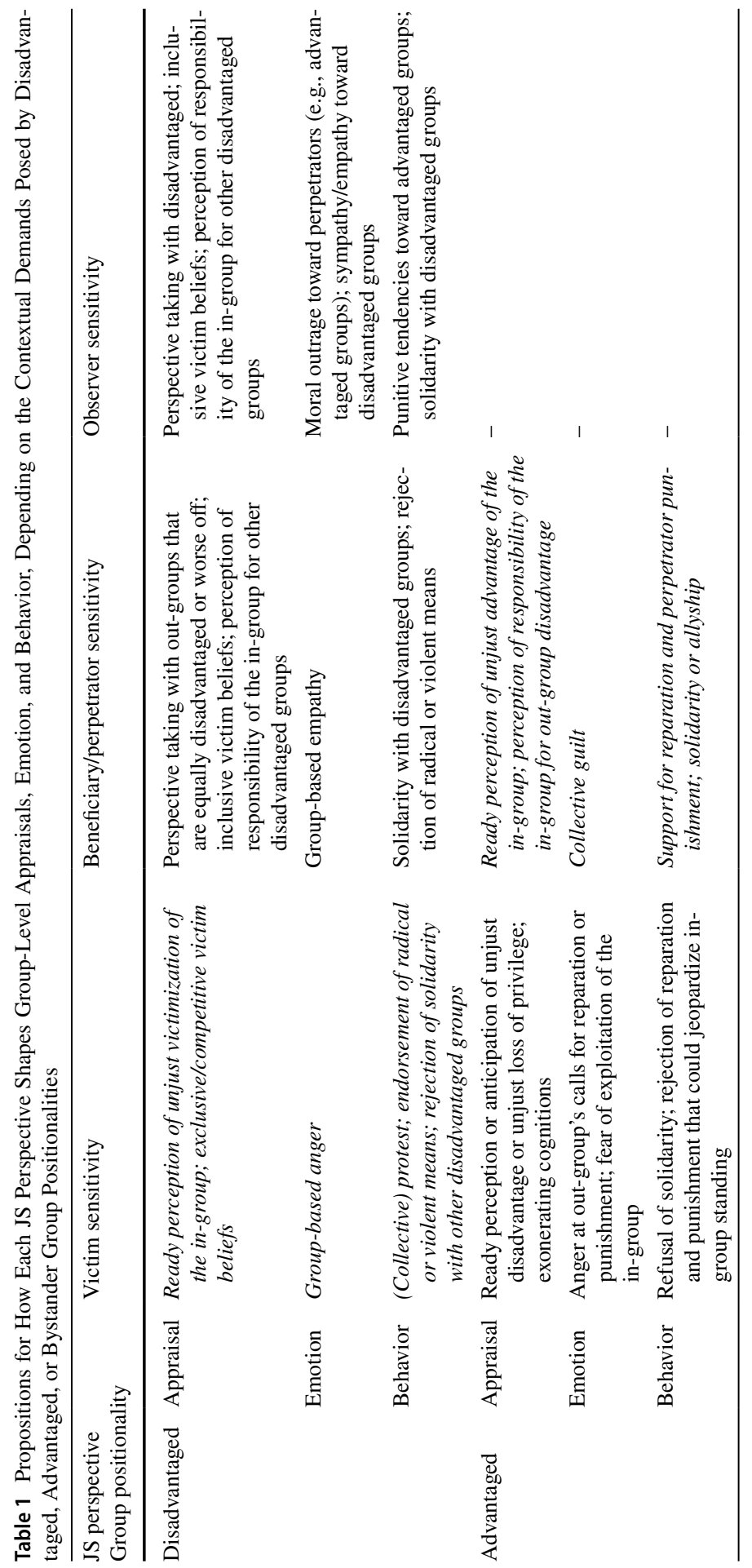




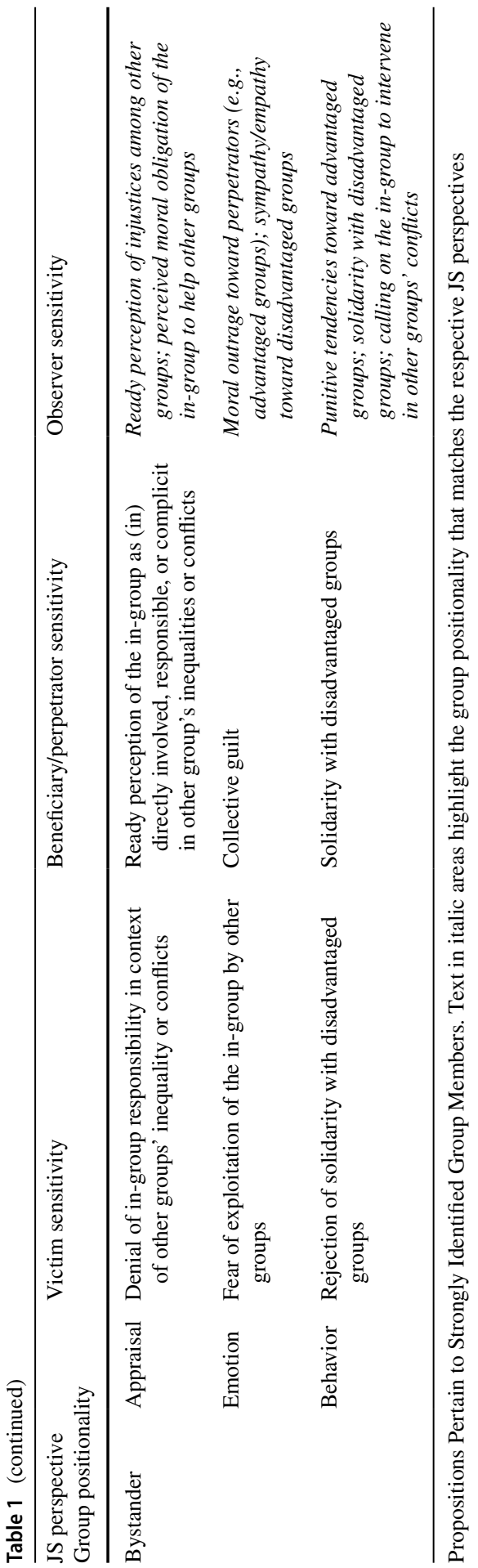


these calls as illegitimate and anticipate unjust victimization of their group. In addition to angry reactions toward out-groups' claims for reparation or punishment, victim sensitivity should also predict more intense fear of exploitation, refusal of solidarity, and rejection of any other steps that could threaten one's group's standing. The results reported by Süssenbach and Gollwitzer (2015) and Rothmund and colleagues $(2017,2020)$ provide the first evidence in this direction. Furthermore, among advantaged group members, victim sensitivity could involve an inclination to legitimize their own group's advantages as legitimate, through the use of exonerating cognitions (e.g., Roccas et al., 2006) and the rejection of any responsibility for disadvantaged groups' circumstances.

Bystander groups are not directly involved in a conflict (or, more generally speaking, relationships) between other groups. Nevertheless, bystander groups can be implicitly or explicitly relevant to inequalities or conflicts between other parties. Accordingly, contextual demands on bystander group members might be shaped by other groups calling on their group to stand witness, take on responsibility, get involved as an ally, or refrain from illegitimate intervention. For people who strongly identify with a bystander group, such contextual cues, we argue, will become selfrelevant "through the lens" of the JS perspectives' characteristic appraisal patterns. Among people who identify highly with their bystander group, more (compared to less) victim-sensitive individuals should worry that the in-group could face disadvantages or lose privileges when intervening in other groups' conflicts. Accordingly, they should tend to deny responsibility of the in-group in other groups' fate, and resist any steps that could jeopardize their in-group's standing.

\section{Potential Specificities of Victim Sensitivity at the Group Level}

So far, our theorizing has been guided by the general assumption that the psychological processes that are involved in how victim sensitivity plays out in interpersonal contexts, become relevant in parallel ways in intergroup contexts, when persons construe themselves as members of a social group and appraise the relationships of their group with other groups. Now, we want to address the possibility that, specifically for victim sensitivity, processes at group and individual levels might be in conflict. In other words, victim sensitivity could entail a conflict between personal and group-based concerns. We know that at the individual level, persons with higher (compared to lower) victim sensitivity tend to fear being exploited and therefore avoid making themselves dependent on the decisions of others (such as in cooperative settings, e.g., Maltese et al., 2016). In group contexts, victim sensitivity could similarly heighten such a personal concern about the possibility that fellow in-group members might exploit one's engagement on behalf of the group, through free-riding (e.g., Stroebe \& Frey, 1982). This personal concern and resulting emotions, such as fear, could counteract the group-based perception of injustices, such that victimsensitive persons could be torn between wanting to act against injustices inflicted on their group, and wanting to avoid their personal engagement being exploited by others. 
These considerations can be debated, since personal concerns might be outweighed by concerns about the in-group when individuals strongly identify as group members. Indeed, in-group mistrust has been found to play less of a role among highly identified (compared to less identified) group members (Gollwitzer et al., 2021). Future research can fruitfully address this stimulating question. For example, a psychological conflict between personal and group-level concerns among victimsensitive group members could manifest such that victim sensitivity correlates with group-based anger and endorsement of collective action, but also with reluctance to become active oneself, especially if taking action would mean bearing personal costs or risks.

\section{Beneficiary and Perpetrator Sensitivities at the Group Level}

In contrast to victim sensitivity, heightened beneficiary and perpetrator sensitivities should imply a readiness to engage in downward group-level comparisons (Maltese, 2015), coupled with a tendency to attribute blame to the in-group. Specifically, among those identified with their group, persons with higher beneficiary or perpetrator sensitivity should readily perceive in-group advantages as illegitimate, see their group as passively or actively involved in causing or perpetuating other groups' disadvantages, and reject attempts at justifying their relative advantages or denying their group's responsibility.

Clearly, such appraisals are afforded by the contextual demands faced by advantaged group members. Under these conditions, beneficiary and perpetrator sensitivities should be predictive of collective guilt among highly identified group members, as well as support for reparation or in-group punishment, and engagement in solidarity or allyship with disadvantaged groups. Results by Gollwitzer et al., (2005, Study 2 ), in the context of the German reunification regarding solidarity of West Germans with East Germans, provide some support for the plausibility of our proposition, albeit the levels of identification were not accounted for in their study. Further support could be drawn from the studies by Rothmund et al., (2017*) on solidarity in the context of the Euro crisis.

With regard to other group positionalities, we argue that beneficiary and perpetrator sensitivities could be relevant also among members of disadvantaged groups. For disadvantaged group members who identify strongly with their group, beneficiary and perpetrator sensitivities might imply concerns for other, possibly even more disadvantaged groups, and a tendency to empathize with those worse off and a motivation to engage against injustices also on their behalf. This notion resonates with the concept of "inclusive victim consciousness" (Vollhardt et al., 2012a, b, 2015) that has been discussed as critical for solidarity and alliance building between victim groups. Furthermore, among highly identified disadvantaged group members, perpetrator sensitivity could specifically involve a concern over perpetration of injustices by their own group. Accordingly, among those strongly identified disadvantaged group members, perpetrator-sensitive people should be predisposed to critically scrutinize their group's actions, with an eye to any unjust consequences for other groups. Moreover, it seems plausible that highly perpetrator-sensitive group 
members would tend to reject violent actions as illegitimate means for their group's goals.

Beneficiary and perpetrator sensitivities could also be relevant among bystander groups to other groups' inequalities or conflicts. Under these contextual demands, identified group members with high (compared to lower) beneficiary or perpetrator sensitivities should be inclined to perceive their own group as indirectly involved, potentially complicit, and as such responsible for the continuation of disparities or the outcomes of conflict between other groups. For example, in some cases, historical relationships could provide a lens through which members of a bystander group perceive their group as responsible for or benefitting from other groups' conflicts. Accordingly, we hypothesize that among bystander groups, highly (compared to more lowly) beneficiary- or perpetrator sensitive individuals who identify with their group will anticipate feelings of collective guilt in the face of inequality or potential atrocities between other groups, and be ready to show solidarity with the disadvantaged.

\section{Potential Specificities of Beneficiary and Perpetrator Sensitivities at the Group Level}

Just as victim sensitivity might trigger tensions between personal and group-level concerns among strongly identified group members, beneficiary and perpetrator sensitivities might also give rise to psychological conflicts among highly identified group members. For advantaged groups, for example, high levels of group identification are typically associated with in-group-defensive tendencies, such as less acceptance of the negative portrayal of the in-group (Branscombe et al., 1999), less collective guilt and more disengagement from in-group-committed harm (Doosje et al., 1998; Li et al., 2020), and less willingness to repair the harm (Doosje et al., 2006). Such in-group-defensive tendencies are therefore at odds with the predisposition to experiencing guilt and assuming responsibility implied by high levels of perpetrator or beneficiary sensitivity. While our propositions rest on the notion that certain level of group identification is needed for individuals to experience collective guilt, strong identification and other-focused JS might result in conflicting cognitions and emotions among advantaged group members.

Furthermore, our propositions treat group identification as a moderator, interacting with the JS perspectives. Additionally, beneficiary and perpetrator sensitivities might themselves have downstream implications for identification. Particularly among advantaged group members, high beneficiary and perpetrator sensitivities could engender in-group-critical appraisals. Similar to individual-level processes (Maltese \& Baumert, 2019), at the group level, beneficiary and perpetrator sensitivities can be expected to correlate negatively with exonerating cognitions and moral disengagement. Consequently, highly beneficiary- or perpetrator-sensitive members of advantaged groups should be predisposed to endure negative in-grouprelated feelings, such as collective guilt. Per implication, this could mean that more (compared to less) beneficiary or perpetrator-sensitive advantaged group members identify with their groups in ways that allow for such critical appraisals, rather than uncritically deferring to in-group norms and stereotypes (Roccas et al., 2006). It will be interesting for future studies to explore the relations between the JS perspectives 
and in-group identification, both in terms of strength and quality, and depending on group positionalities. Note that in our framework, as depicted in Fig. 1, we currently do not account for any links between the JS perspectives and identification. Potentially, the framework needs to be extended based on future empirical findings.

\section{Observer Sensitivity at the Group Level}

Observer sensitivity functions distinctly from the other JS perspectives in that it entails the ready perception of and intense reactions to injustices from an uninvolved and unaffected point of view. At the interpersonal level, observer sensitivity has been found to shape the reactions of third parties toward injustices that occur between other people (e.g., Lotz et al., 2011). At the group level, this could mean that more (compared to less) observer-sensitive persons would be inclined to perceive and react to injustices between groups to which they do not belong. Accordingly, observer sensitivity should be relevant for reactions of bystander group members. From this group positionality, observer sensitivity should foster moral outrage and punitive inclinations toward those seen as responsible (e.g., advantaged groups), and sympathy toward and solidarity with the disadvantaged. Specifically, for highly identified members of bystander groups, observer sensitivity might entail a strong sense of moral obligation of the in-group to help other groups and consequently a readiness to call upon the in-group to take steps against perceived injustice.

What about the contextual demands posed by other group positionalities? It is conceivable that observer sensitivity might be relevant among disadvantaged group members, by shaping the extent to which they are concerned about the injustices inflicted on other groups. As such, for highly identified members of disadvantaged groups, observer sensitivity might foster a sense of inclusive victimhood (Vollhardt, 2015) and moral obligation (Vollhardt \& Staub, 2011; Warner et al., 2014), and motivate solidarity, similar to the consequences that we discussed for beneficiary and perpetrator sensitivities.

For advantaged group members, by contrast, it seems that, among those highly identified, observer sensitivity might be less relevant than the other JS perspectives. The contextual demands of advantaged groups should make the group's involvement and responsibility salient, so that identified group members would not tend to adopt an uninvolved observer perspective with regard to the respective group constellation. Under these group circumstances, beneficiary and perpetrator sensitivities seem much more likely to be predictive of emotional and behavioral reactions than observer sensitivity.

\section{Potential Specificities of Observer Sensitivity at the Group Level}

Since observer sensitivity should shape how individuals perceive and are concerned about injustices between groups which they do not belong to themselves, it also seems possible that identification with one's own group might be irrelevant for how observer sensitivity plays out. In other words, observer sensitivity might shape individual-level rather than group-level reactions to other groups' inequality or conflicts. As we have argued above, however, group identification might influence how much 
observer sensitivity predicts individuals' perception of their own group as responsible, and call on their group to intervene in other groups' conflicts, instead of or in addition to taking individual action. Future research could therefore shed light on the importance of group identification for group-level consequences of observer sensitivity. Furthermore, it is also worthwhile exploring whether observer sensitivity might be linked to a broader scope of justice (Opotow, 1995) or more inclusive identification (e.g., identification with humanity, McFarland et al., 2012).

\section{Conclusions and Directions for Further Refinements-Research Needed}

Since the inception of JS as a personality construct, extensive research has shed light on the individual-level processes involved in how JS from the different perspectives of victim, beneficiary, perpetrator, or observer, shapes perceptions of and reactions to injustices (e.g., Baumert \& Schmitt, 2016). Given that (in)justice is an important social phenomenon in interpersonal as much as in intergroup relations, researchers have started to address the relevance of the JS perspectives in intergroup contexts. Here, we have proposed a theoretical framework that can guide future research to understand when and how the JS perspectives should become relevant for shaping group-level appraisals, emotion, and behavior, in intergroup contexts. We argue that, when individuals identify strongly with a social group, justice-related personality dynamics get "lifted" to the group level. This means that individual differences in the JS perspectives shape how individuals construe and react to how their group relates to other groups, independent of how they are affected as individuals. Moreover, we emphasize that the effects of the JS perspectives at the group level should depend on the contextual demands posed by different group positionalities of disadvantaged, advantaged, or bystander groups.

Clearly, empirical research is needed to comprehensively test the propositions that we have derived within our framework (Table 1). We would advocate for a multi-methodological approach combining field studies on individual differences in actual experience and behavior among existing groups, with laboratory-based studies that would allow experimental manipulation of group positionalities. Based on our framework, such a research program promises a well-rounded understanding of the JS perspectives. Beyond testing how individual-level processes of JS would "translate" to the group level, future research can provide novel insights, for instance, regarding potential psychological conflicts between group-level and personal concerns. Furthermore, research guided by our framework can shed light on how and under which circumstances the JS perspectives predict the legitimization of violence as a means to achieve group goals. By pointing to the potential relevance of group positionalities and degrees of group identification, our framework could help clarify the mixed pattern of results obtained so far, with regard to the JS perspectives and radicalization (Jahnke et al., 2020; Macdougall et al., 2018).

Another interesting observation that results from our framework relates to the normative implications of the JS perspectives, and particularly victim sensitivity. While we attempted to remain descriptive in our account of the previously shown 
correlates of victim sensitivity at the individual level, it is quite clear that these downstream consequences are considered to be antisocial. Indeed, they include the reluctance to cooperate with others or forgive them, and the tendency to legitimize one's own wrongdoings (e.g., Gollwitzer et al., 2005, 2013). Interestingly, however, the group-level processes that we expect will result from victim sensitivity among disadvantaged group members, including group-based anger and willingness to engage in protest on behalf of one's group, represent important facilitators of individuals' engagement in fighting against injustices. If subsequent empirical findings do indeed support these propositions, they could also have a bearing on the current normative conceptualization of victim sensitivity.

A research program testing the propositions derived from our framework could also provide important insights beyond the understanding of the JS perspectives. For instance, research on the roles of group identification in intergroup contexts has yielded complex patterns of results. On the one hand, strong group identification can have conflict-enhancing effects (Li et al., 2020; Roccas \& Elster, 2012); on the other hand, it can also foster group-based emotions, such as collective guilt or group-based sympathy, that are conducive of intergroup reconciliation (e.g., Branscombe \& Miron, 2004; Doosje et al., 1998; Shuman et al., 2018). Taking into account interindividual differences in how intergroup relations are appraised might be one promising approach to understanding these diverging results. More broadly speaking, our framework for the JS perspectives in intergroup contexts might provide an example of how to conceptualize the relevance of personality dynamics in intergroup relations.

\section{Potential for Further Refinement of our Framework}

Despite the apparent usefulness of our framework to inform a comprehensive set of hypotheses regarding the JS perspectives in intergroup contexts, the framework represents an (over-)simplification in various regards. We would like to mention some ways in which we anticipate that future research findings might inform extensions or modifications of our framework. For instance, in our framework, we take into account three group positionalities-disadvantaged, advantaged, and bystander groups-that arguably involve distinct contextual demands and affordances for group members. Clearly, more fine-grained distinctions are possible. Notably, differentiating between more direct and indirect roles of advantaged groups could allow us to spell apart consequences of perpetrator and beneficiary sensitivities, the two JS perspectives that we treated in common subchapters.

As another limitation of the presented framework, we have worked out predictions exclusively for individuals who are strongly identified with their group (Table 1). Because of our focus on the relevance of the JS perspectives for grouplevel processes, we did not spell out predictions for those weakly identified with their group. As a consequence, the role of identification as a moderator remains underspecified. This role is most likely a complex one, because, for those weakly identified, the consequences of the JS perspectives should depend on the ways in which individual concerns are affected by the potential injustices, whereas for 
those strongly identified, group positionalities should be (more) relevant. Accordingly, one important avenue for future research will be to explore the extent to which identification is a crucial moderator of the differently hypothesized links between the JS perspectives and their downstream correlates.

Relatedly, as it currently stands, our framework is explicitly symmetrical, in that it assumes that high identification with the relevant group is equally important across the different group positionalities (i.e., disadvantaged, advantaged, bystander) that we discuss. It is, however, conceivable that identification is a less crucial factor among members of disadvantaged groups. Drawing on Self-Categorization Theory (Turner et al., 1987), we believe it is plausible that for members of disadvantaged groups, the relationships between the JS perspectives and the different resulting appraisals, emotions, and behaviors exist for both high and low identifiers. This is because the disadvantage or victimization of the in-group potentially poses such strong contextual demands that psychological identification with the group is not necessary for individuals to respond to them at the group level (see Schmitt et al., 2013). Indeed, in line with van Zomeren et al.'s (2004) observation, while the social identity approach posits identification as a precursor for perceptions of collective disadvantage, severe disadvantage itself may draw attention to group-level outcomes and generate group-level appraisals and behaviors (Tajfel et al., 1979).

In a similar vein, future research should scrutinize another proposed symmetry of our model; namely the assumption that the JS perspectives play equally important roles across the different group positionalities. In parallel to the previous note on identification among disadvantaged groups, and as Süssenbach and Gollwitzer (2015) have speculated, it is possible that victim sensitivity, specifically, will be less determining of group-level appraisals among members of victimized groups. The logic remains the same; severe disadvantage potentially neutralizes the effects of this interindividual difference variable, and cedes way for more uniform appraisals among group members, who might react homogeneously as if they were all high on victim sensitivity. In other words, severe group-based disadvantage might provide contextual demands that can be characterized as strong situations, as conceptualized by Mischel (1973) and Schmitt et al. (2013). This question can of course further be extended beyond the particular victim JS perspective and the disadvantaged positionality, to a broader pondering in line with person-in-context approaches to personality and social psychology. Specifically, we can ask under what circumstances group influences are strong enough to homogenize individual differences in sensitivity to injustice, through material and/or normative mechanisms which flatten the role of personality. These are empirical questions that we argue should be explored.

Lastly, with our framework, we have started to spell out how and under which conditions the JS perspectives should shape group-level experience and behavior. Conversely, group-level experiences might also impact individual dispositions in ways that are retained over time and generalized across situations (e.g., MendozaDenton et al., 2002). Research on personality development has clarified that life experiences can impact personality in enduring ways. Similarly, significant events at the group level that are experienced as self-relevant by strongly identified group members could have such impact as well ( $\mathrm{Li}$ et al., 2021). We therefore believe that 
integrating intergroup research with research on personality development promises exciting avenues.

To conclude, JS as a personality construct has stimulated fruitful theorizing and research on individual differences in the processing of and reactions to injustices at the interpersonal level. With our framework, we hope to provide the basis for a comprehensive understanding of the JS perspectives in intergroup contexts. As such, our framework can help clarify the mixed findings in the literature, and provide promising directions for future research on the experiences of and reactions to injustices at the group level.

Author Contribution Special Issue in SJR “Social Justice: Lessons learned and needed research.”

Funding Open Access funding enabled and organized by Projekt DEAL.

\section{Declarations}

Conflict of interest We declare that there is no conflict of interest.

Open Access This article is licensed under a Creative Commons Attribution 4.0 International License, which permits use, sharing, adaptation, distribution and reproduction in any medium or format, as long as you give appropriate credit to the original author(s) and the source, provide a link to the Creative Commons licence, and indicate if changes were made. The images or other third party material in this article are included in the article's Creative Commons licence, unless indicated otherwise in a credit line to the material. If material is not included in the article's Creative Commons licence and your intended use is not permitted by statutory regulation or exceeds the permitted use, you will need to obtain permission directly from the copyright holder. To view a copy of this licence, visit http://creativecommons.org/licen ses/by/4.0/.

\section{References}

Alicke, M. D. (2000). Culpable control and the psychology of blame. Psychological Bulletin, 126, $556-574$.

Ball, T. C., \& Branscombe, N. R. (2019). When do groups with a victimized past feel solidarity with other victimized groups? In R. K. Mallett \& M. J. Monteith (Eds.), Confronting Prejudice and Discrimination (pp. 73-92). Academic Press.

Baumert, A., \& Schmitt, M. (2016). Justice sensitivity. In C. Sabbagh \& M. Schmitt (Eds.), Handbook of Social Justice Theory and Research (pp. 161-180). Springer.

Baumert, A., Beierlein, C., Schmitt, M., Kemper, C. J., Kovaleva, A., Liebig, S., \& Rammstedt, B. (2014a). Measuring four perspectives of justice sensitivity with two items each. Journal of Personality Assessment, 96, 380-390.

Baumert, A., Schlösser, T., \& Schmitt, M. (2014b). Economic games-Performance-based assessment of altruism and fairness. European Journal of Psychological Assessment, 30, 178-192.

Baumert, A., Schmitt, M., Perugini, M., Johnson, W., Blum, G., Borkenau, P., Costantini, G., Denissen, J. J. A., Fleeson, W., Grafton, B., Jayawickreme, E., Kurzius, E., MacLeod, C., Miller, L. C., Read, S. J., Roberst, B., Robinson, M. D., Wood, D., \& Wrzus, C. (2017). Integrating personality structure, personality process, and personality development. European Journal of Personality, 31(5), 503-528.

Baumert, A., Maltese, S., Reis, D., MacLeod, C., Tan-Mansukhani, R., Galang, A. J. R., Salanga, M. G. C., \& Schmitt, M. (2020). A cross-cultural study of justice sensitivity and its consequences for 
cooperation. Social Psychological and Personality Science. https://doi.org/10.1177/1948550619 896895

Baumert, A., Maltese, S., \& Lischetzke, T. (2021). Linking the momentary processing of suffered or committed injustice to intraindividual dispositional change in justice sensitivity from the victim and perpetrator perspectives. Manuscript under review.

Bondü, R., Rothmund, T., \& Gollwitzer, M. (2016). Mutual long-term effects of school bullying, victimization, and justice sensitivity in adolescents. Journal of Adolescence, 48, 62-72. https://doi.org/10. 1016/j.adolescence.2016.01.007

Branscombe, N. R., \& Miron, A. M. (2004). Interpreting the ingroup's negative actions toward another group: Emotional reactions to appraised harm. In L. Z. Tiedens \& C. W. Leach (Eds.), The Social Life of Emotions (pp. 314-335). Cambridge University Press. https://doi.org/10.1017/CBO9780511 819568.017

Branscombe, N. R., Ellemers, N., Spears, R., \& Doosje, B. (1999). The context and content of social identity threat. Social identity: Context, Commitment, Content, 35-58.

Crosby, F. (1976). A model of egoistical relative deprivation. Psychological Review, 83, 85-113.

Doosje, B., Branscombe, N. R., Spears, R., \& Manstead, A. S. (1998). Guilty by association: When one's group has a negative history. Journal of Personality and Social Psychology, 75(4), 872-886.

Doosje, B. E., Branscombe, N. R., Spears, R., \& Manstead, A. S. (2006). Antecedents and consequences of group-based guilt: The effects of ingroup identification. Group Processes \& Intergroup Relations, 9(3), 325-338.

Funder, \& D. C . (2004). The personality puzzle (3rd ed.). W. W. Norton.

Gerlach, T. M., Allemand, M., Agroskin, D., \& Denissen, J. J. A. (2012). Justice sensitivity and forgiveness in close interpersonal relationships: The mediating role of mistrustful, legitimizing, and prorelationship cognitions. Journal of Personality, 80, 1373-1413.

Gollwitzer, M., \& Rothmund, T. (2009). When the need to trust results in unethical behavior: The Sensitivity to Mean Intentions (SeMI) model. In D. de Cremer (Ed.), Psychological Perspectives on Unethical Behavior and Decision Making (pp. 135-152). Information Age.

Gollwitzer, M., \& Rothmund, T. (2011). What exactly are victim-sensitive persons sensitive to? Journal of Research in Personality, 45, 448-455.

Gollwitzer, M., Schmitt, M., Schalke, R., Maes, J., \& Baer, A. (2005). Asymmetrical effects of justice sensitivity perspectives on prosocial and antisocial behavior. Social Justice Research, 18, 183-201.

Gollwitzer, M., Rothmund, T., \& Süssenbach, P. (2013). The Sensitivity to Mean Intentions (SeMI) model: Basic assumptions, recent findings, and potential avenues for future research. Social and Personality Psychology Compass, 7(7), 415-426.

Gollwitzer, M., Magraw-Mickelson, Z., Vollan, B., \& Süssenbach, P. (2021). Victim sensitivity in groups: When is one a detriment to all? Journal of Theoretical Social Psychology, 5(1), 3-13. https://doi. org/10.1002/jts5.76

GoogleScholar (2021). [retrieved March 15, 2021].

Iyer, A., \& Leach, C. W. (2008). Emotion in inter-group relations. European Review of Social Psychology, 19(1), 86-125. https://doi.org/10.1080/10463280802079738

Jahnke, S., Schröder, C. P., Goede, L.-R., Lehmann, L., Hauff, L., \& Beelmann, A. (2020). Observer sensitivity and early radicalization to violence among young people in Germany. Social Justice Research, 33, 308-330. https://doi.org/10.1007/s11211-020-00351-y

Jost, J. T., Pelham, B. W., Sheldon, O., \& Ni Sullivan, B. (2003). Social inequality and the reduction of ideological dissonance on behalf of the system: Evidence of enhanced system justification among the disadvantaged. European Journal of Social Psychology, 33(1), 13-36.

Leach, C. W., Snider, S., \& Iyer, A. (2002). "Poisoning the consciences of the fortunate": The experience of relative advantage and support for social equality. In I. Walker \& H. J. Smith (Eds.), Relative Deprivation: Specification, Development, and Integration (pp. 136-163). Cambridge University.

Leach, C. W., Iyer, A., \& Pedersen, A. (2006). Anger and guilt about ingroup advantage explain the willingness for political action. Personality and Social Psychology Bulletin, 32(9), 1232-1245.

Li, M., \& Leidner, B. (2019). Understanding intergroup violence and its aftermath from perpetrator and victim perspectives. In L. S. Newman (Ed.), Confronting Humanity at its Worst: Social Psychological Perspectives on Genocide (pp. 157-194). Oxford University Press.

Li, M., Leidner, B., \& Fernandez-Campos, S. (2020). Stepping into perpetrators' shoes: How ingroup transgressions and victimization shape support for retributive justice through perspective-taking with perpetrators. Personality and Social Psychology Bulletin, 46(3), 424-438. 
Li, M., Sasse, J., Sckopke, A., \& Baumert, A. (2021). Standing up against moral transgressions: An integrative perspective on the socio-psychological antecedents and barriers to moral courage. Manuscript in preparation.

Lotz, S., Baumert, A., Schlösser, T., Gresser, F., \& Fetchenhauer, D. (2011). Individual differences in third-party interventions: How justice sensitivity shapes altruistic punishment. Negotiation and Conflict Management, 4, 297-313.

Lotz, S., Schlösser, T., Cain, D. M., \& Fetchenhauer, D. (2013). The (in)stability of social preferences: Using justice sensitivity to predict when altruism collapses. Journal of Economic Behavior and Organization, 93, 141-148.

Macdougall, A. I., van der Veen, J., Feddes, A. R., Nickolson, L., \& Doosje, B. (2018). Different strokes for different folks: The role of psychological needs and other risk factors in early radicalisation. International Journal of Developmental Science, 12(1-2), 37-50. https://doi.org/10.3233/ DEV-170232

Mackie, D. M., Smith, E. R., \& Ray, D. G. (2008). Intergroup emotions and intergroup relations. Social and Personality Psychology Compass, 2(5), 1866-1880.

Maltese, S. (2015). Do interpretational tendencies translate justice sensitivity into behavioral reactions? Development and test of the Beneficiary-Sensitivity-Model Dissertation thesis. Germany: University of Koblenz-Landau.

Maltese, S., \& Baumert, A. (2019). Linking longitudinal dynamics of justice sensitivity and moral disengagement. Personality and Individual Differences, 136, 173-177. https://doi.org/10.1016/j.paid. 2017.06.041

Maltese, S., Baumert, A., Schmitt, M. J., \& MacLeod, C. (2016). How victim sensitivity leads to uncooperative behavior via expectancies of injustice. Frontiers in Psychology, 6, 2059. https://doi.org/10. 3389/fpsyg.2015.02059

McFarland, S., Webb, M., \& Brown, D. (2012). All humanity is my ingroup: A measure and studies of identification with all humanity. Journal of Personality and Social Psychology, 103(5), 830-853. https://doi.org/10.1037/a0028724

Mendoza-Denton, R., Downey, G., Purdie, V. J., Davis, A., \& Pietrzak, J. (2002). Sensitivity to statusbased rejection: Implications for African American students' college experience. Journal of Personality and Social Psychology, 83(4), 896-918. https://doi.org/10.1037/0022-3514.83.4.896

Merton, R. K., \& Kitt, A. S. (1950). Contributions to the theory of reference group behavior. In R. K. Merton \& P. F. Lazarsfeld (Eds.), Continuities in Social Research: Studies in the Scope and Method of "The American Soldier (pp. 40-105). Free Press.

Mischel, W. (1973). Toward a cognitive social learning reconceptualization of personality. Psychological review, 80(4), 252.

Mikula, G. (2003). Testing an attribution-of-blame model of judgments of injustice. European Journal of Social Psychology, 33(6), 793-811.

Mohiyeddini, C., \& Schmitt, M. J. (1997). Sensitivity to befallen injustice and reactions to unfair treatment in a laboratory situation. Social Justice Research, 10(3), 333-353.

Montada, L. (2007). Justice conflicts and the justice of conflict resolution. In K. Törnblom \& R. Vermunt (Eds.), Distributive and Procedural Justice. Research and Applications (pp. 255-268). Ashgate.

Nelson, J. K., Hynes, M., Sharpe, S., Paradies, Y., \& Dunn, K. (2018). Witnessing anti-white 'racism': White victimhood and 'reverse racism'in Australia. Journal of Intercultural Studies, 39(3), 339-358.

Niesta Kayser, D., Greitemeyer, T., Fischer, P., \& Frey, D. (2010). Why mood affects help giving, but not moral courage: Comparing two types of prosocial behaviour. European Journal of Social Psychology, 40(7), 1136-1157.

Noor, M., Vollhardt, J. R., Mari, S., \& Nadler, A. (2017). The social psychology of collective victimhood. European Journal of Social Psychology, 47(2), 121-134. https://doi.org/10.1002/ejsp.2300

Opotow, S. (1995). Drawing the line: Social categorization, moral exclusion, and the scope of justice. In B. B. Bunker \& J. Z. Rubin (Eds.), Conflict, Cooperation, and Justice: Essays Inspired by the Work of Morton Deutsch (pp. 347-369). Jossey-Bass.

Roccas, S., \& Elster, A. (2012). Group identities. In L. A. Tropp (Ed.), The Oxford Handbook of Intergroup Conflict (pp. 106-122). Oxford University Press. https://doi.org/10.1093/oxfordhb/97801 99747672.013.0007

Roccas, S., Klar, Y., \& Liviatan, I. (2006). The paradox of group-based guilt: Modes of national identification, conflict vehemence, and reactions to the in-group's moral violations. Journal of Personality and Social Psychology, 91(4), 698-711. 
Rothmund, T., Stavrova, O., \& Schlösser, T. (2017). Justice concerns can feed nationalistic concerns and impede solidarity in the euro crisis: How victim sensitivity translates into political attitudes. Social Justice Research, 30(1), 48-71. https://doi.org/10.1007/s11211-017-0280-7

Rothmund, T., Bromme, L., \& Azevedo, F. (2020). Justice for the people? How justice sensitivity can foster and impair support for populist radical-right parties and politicians in the United States and in Germany. Political Psychology, 41(3), 479-497. https://doi.org/10.1111/pops.12632

Rothschild, Z. K., \& Keefer, L. A. (2018). Righteous or self-righteous anger? Justice sensitivity moderates defensive outrage at a third-party harm-doer. European Journal of Social Psychology, 48(4), 507-522. https://doi.org/10.1002/ejsp.2349

Runciman, W. G., \& Runciman, B. (1966). Relative deprivation and social justice: A study of attitudes to social inequality in twentieth-century England. American Sociological Review, 32(1), 132-133. https://doi.org/10.2307/2091734

Saab, R., Tausch, N., Spears, R., \& Cheung, W. Y. (2015). Acting in solidarity: Testing an extended dual pathway model of collective action by bystander group members. British Journal of Social Psychology, 54(3), 539-560.

Sasse, J., Halmburger, A., \& Baumert, A. (2020). The functions of anger in moral courage-Insights from a behavioral study. Emotion. Advance online publication. https://doi.org/10.1037/emo00 00906

Scherer, K. R., Schorr, A., \& Johnstone, T. (Eds.). (2001). Appraisal Processes in Emotion: Theory, Methods. Oxford University Press.

Schlösser, T., Berger, S., \& Fetchenhauer, D. (2018a). Justice sensitivity and cooperation dynamics in repeated public good games. Social Justice Research, 31(1), 1-22. https://doi.org/10.1007/ s11211-017-0300-7

Schlösser, T., Steiniger, T., Ehlebracht, D., \& Fetchenhauer, D. (2018b). How justice sensitivity predicts equality preferences in simulated democratic systems. Journal of Research in Personality, 73, 75-81. https://doi.org/10.1016/j.jrp.2017.11.005

Schmitt, M. (1996). Individual differences in Sensitivity to Befallen Injustice (SBI). Personality and Individual Differences, 21, 3-20.

Schmitt, M. J., \& Mohiyeddini, C. (1996). Sensitivity to Befallen Injustice and reactions to a real-life disadvantage. Social Justice Research, 9(3), 223-238.

Schmitt, M., Gollwitzer, M., Maes, J., \& Arbach, D. (2005). Justice sensitivity: Assessment and location in the personality space. European Journal of Psychological Assessment, 21, 202-211.

Schmitt, M., Baumert, A., Gollwitzer, M., \& Maes, J. (2010). The Justice Sensitivity Inventory: Factorial validity, location in the personality facet space, demographic pattern, and normative data. Social Justice Research, 23, 211-238.

Schmitt, M., Gollwitzer, M., Baumert, A., Blum, G. S., Gschwendner, T., Hofmann, W., \& Rothmund, T. (2013). Proposal of a nonlinear interaction of person and situation (NIPS) model. Frontiers in Psychology, 4, 499.

Schulte-Braucks, J., Baethge, A., Dormann, C., \& Vahle-Hinz, T. (2019). Get even and feel good? Moderating effects of justice sensitivity and counterproductive work behavior on the relationship between illegitimate tasks and self-esteem. Journal of Occupational Health Psychology, 24(2), 241-255. https://doi.org/10.1037/ocp0000112

Shaver, K. G. (Ed.). (1985). The Attribution of Blame: Causality, Responsibility, and Blameworthiness. Springer.

Shuman, E., Johnson, D., Saguy, T., \& Halperin, E. (2018). Threat to the group's image can motivate high identifiers to take action against in-group transgressions. Personality and Social Psychology Bulletin, 44(11), 1523-1544. https://doi.org/10.1177/0146167218768800

Smith, E. R. (1993). Social identity and social emotions: Toward new conceptualizations of prejudice. In D. M. Mackie \& D. L. Hamilton (Eds.), Affect, Cognition, and Stereotyping (pp. 297-315). Academic Press.

Smith, E. R., \& Mackie, D. M. (2015). Dynamics of group-based emotions: Insights from intergroup emotions theory. Emotion Review, 7(4), 349-354.

Smith, H. J., Cronin, T., \& Kessler, T. (2008). Anger, fear, or sadness: Faculty members' emotional reactions to collective pay disadvantage. Political Psychology, 29(2), 221-246.

Stavrova, O., \& Schlösser, T. (2015). Solidarity and social justice: Effect of individual differences in justice sensitivity on solidarity behaviour. European Journal of Personality, 29(1), 2-16. https:// doi.org/10.1002/per.1981 
Stroebe, W., \& Frey, B. S. (1982). Self-interest and collective action: The economics and psychology of public goods. British Journal of Social Psychology, 21(2), 121-137.

Süssenbach, P., \& Gollwitzer, M. (2015). Us(ed): The role of victim sensitivity in potentially exploitative intergroup relationships. Group Processes \& Intergroup Relations. 18(2), 241-255. https:// doi.org/10.1177/1368430214556700

Tajfel, H. E. (Ed.). (1978). Differentiation Between Social Groups: Studies in the Social Psychology of Intergroup Relations. Academic Press.

Tajfel, H., Turner, J. C., Austin, W. G., \& Worchel, S. (1979). An integrative theory of intergroup conflict. Organizational Identity: A Reader, 56(65), 9780203505984-16.

Tham, Y. J., Hashimoto, T., \& Karasawa, K. (2019). The positive and negative effects of justice sensitivity and justice-related emotions in the volunteer's dilemma. Personality and Individual Differences, 151, 109501. https://doi.org/10.1016/j.paid.2019.07.011

Toribio-Flórez, D., Sasse, J., \& Baumert, A. (2021). Proof under reasonable doubt”: Ambiguity of the norm violation as boundary condition of third-party punishment. Manuscript under review.

Turner, J. C., Hogg, M. A., Oakes, P. J., Reicher, S. D., \& Wetherell, M. S. (1987). Rediscovering the Social Group: A Self-Categorization Theory. Basil Blackwell.

van Zomeren, M., Spears, R., Fischer, A. H., \& Leach, C. W. (2004). Put your money where your mouth is! Explaining collective action tendencies through group-based anger and group efficacy. Journal of Personality and Social Psychology, 87(5), 649-664.

van Zomeren, M., Leach, C. W., \& Spears, R. (2012). Protesters as "passionate economists" a dynamic dual pathway model of approach coping with collective disadvantage. Personality and Social Psychology Review, 16(2), 180-199.

Vollhardt, J. R. (2012a). Collective victimization. In L. R. Tropp (Ed.), Oxford Library of Psychology. The Oxford Handbook of Intergroup Conflict (pp. 136-157). Oxford University Press.

Vollhardt, J. R. (2012b). Interpreting rights and duties after mass violence. Culture \& Psychology, 18(1), $133-145$.

Vollhardt, J. R. (2015). Inclusive victim consciousness in advocacy, social movements, and intergroup relations: Promises and pitfalls. Social Issues and Policy Review, 9(1), 89-120.

Vollhardt, J. R., \& Staub, E. (2011). Inclusive altruism born of suffering: The relationship between adversity and prosocial attitudes and behavior toward disadvantaged outgroups. American Journal of Orthopsychiatry, 81(3), 307.

Walker, I., \& Smith, H. (Ed.). (2002). Relative deprivation. Cambridge University Press.

Warner, R. H., Wohl, M. J., \& Branscombe, N. R. (2014). When do victim group members feel a moral obligation to help suffering others? European Journal of Social Psychology, 44(3), 231-241.

Weiss, H. M., Suckow, K., \& Cropanzano, R. (1999). Effects of justice conditions on discrete emotions. Journal of Applied Psychology, 84, 786-794.

Publisher's Note Springer Nature remains neutral with regard to jurisdictional claims in published maps and institutional affiliations. 